\title{
How do vulnerable road users look at road safety? International comparison based on ESRA data from 25 countries
}

\author{
Katrien Torfs ${ }^{\mathrm{a}, *}$, Uta Meesmann ${ }^{\mathrm{a}, \mathrm{b}}$ \\ ${ }^{a}$ Knowledge Centre Road Safety, Vias Institute, Haachtsesteenweg 1405, BE-1130 Brussels, Belgium \\ ${ }^{\mathrm{b}}$ University of Liège, ArGEnCo/UEE - Local Environment Management \& Analysis (LEMA), Quartier Polytech 1, Allée de la Découverte 9, BE-4000 Liège, Belgium
}

\section{A R T I C L E I N F O}

\section{Article history:}

Received 12 February 2018

Received in revised form 13 March 2019

Accepted 2 April 2019

\section{Keywords:}

Vulnerable road users

Safety culture

Attitudes

Self-reported behavior

\begin{abstract}
A B S T R A C T
The overall aim of the ESRA project is to provide scientific support to road safety policy by generating comparable national data on the current road safety situation. The first ESRA survey was conducted online using representative samples $(\mathrm{N}=1000)$ of the national adult populations in 25 countries across the world. The field work was carried out in two waves: (1) June/July 2015, and (2) November 2016. In total, the first ESRA1 survey covers almost 27,000 respondents, among which roughly 21,000 were identified as vulnerable road users.

Vulnerable road users such as pedestrians, cyclists, or motorcyclists suffer the most severe consequences in road crashes with other road users, because they cannot protect themselves against the speed and mass of the other party. Given their high vulnerability, these types of road users are of special interest to policy makers.

The objective of this paper is to present the ESRA1 results regarding the safety attitudes of vulnerable road users. Special attention was given to 'road crash involvement', 'safety feeling', and 'self-reported unsafe traffic behavior' (i.e., the use of headphone and (motor)cycle helmet). Results show that vulnerable road users were more involved in road crashes compared to car drivers and that they feel less safe. Pedestrians feel safer in traffic compared to other types of vulnerable road users. Logistic regression models show that the use of headphones while walking and cycling is associated with gender, age, and support of policy measures. The use of a (motor)cycle helmet is associated with age and support of policy measures.

The ESRA project has shown the feasibility and the added value of joint data collection by a network of road safety organizations. The intention is to extend the ESRA survey to an increasing number of countries and to repeat it on a triennial basis.
\end{abstract}

(c) 2019 Elsevier Ltd. All rights reserved.

\section{Introduction}

\subsection{Vulnerable road users}

There are a number of ways to define groups of vulnerable road users. A fundamental criterion in all definitions is the lack of external protection (e.g. pedestrians, cyclists, motorcyclists) (OCDE/OECD, 1998). Furthermore, definitions often refer to a lack of task capability such as the inexperience of children or a declining task capability (and physical frailty) of the elderly

\footnotetext{
* Corresponding author.

E-mail address: katrien.torfs@vias.be (K. Torfs).
} 
(SWOV, 2012). Hence, depending on the definition, vulnerable road users are often subdivided by transport mode or by age. In this paper, we opted for a subdivision by transport mode which is based on respondents' self-reported individual traffic exposure. The groups of vulnerable road users studied here are pedestrians, cyclists, and motorcyclists. These road user types are indeed at risk, because they lack external protection. They cannot protect themselves against the speed and mass of the other party in a road crash. Consequently, they suffer the most severe consequences in crashes with other road users (Van Kampen, 2000). Pedestrians and cyclists comprise around $21 \%$ and $8 \%$, respectively, of all road traffic deaths in EU countries; 5500 pedestrians and 2000 cyclists were killed in 2013 alone. Almost 73,300 pedestrians and 25,000 cyclists were killed since 2004 (ETSC, 2015).

The vulnerability of different road user groups in severe crashes can be compared by calculating the inequality factor, which is defined as the ratio of the numbers of casualties of the weaker party to those of the stronger party (SWOV, 2012). The higher the inequality factor is, the higher the vulnerability of road user type is likely to be. Results based on a Dutch sample of crashes between two road users (single road user crashes were not included) during the period 20052009, show that the inequality factor remains far below ten for road crashes between two parties of the unprotected road user group (pedestrians, cyclists, (light-) moped riders, and motorcyclists). The inequality factor increases to a multiple of ten as soon as one of the parties is a car, van, or lorry. The differences in speed and mass as well as the lack of protection are seen as the main risk factors for an increased casualty of vulnerable road users (SWOV, 2012). Hence, these types of road users should be given special attention in road safety policy as recommended in 2010 by the U.N. General Assembly. Furthermore, they predicted that the concern for the safe traffic participation of vulnerable road users will almost certainly rise in the coming years, as the trend towards urbanization continues (United Nations, 2010).

\subsection{Monitoring road safety attitudes}

Trends in road safety performance and the success of policy measures can be monitored using road safety indicators. Important data sources to assess the road safety situation are road crash statistics, road side surveys, and questionnaire surveys. The last source, in particular if it is conducted online, is a relatively inexpensive way to obtain indicators on safety culture and road users' behavior. However, it relies on self-reported information which might be prone to factors such as social desirability in responses. A main advantage of questionnaire surveys is that they can provide insights into socio-cognitive determinants of behavior, such as attitudes, perceived social norm, risk perception, or existing habits. Socio-cognitive factors can help to understand the underlying motivations of certain behavior (Ajzen, 1991; Rogers, 1975; Rosenstock, 1974). It is tempting to use such indicators based on questionnaire surveys for benchmarking purposes. However, the results of national surveys are seldom comparable across countries, because of differences in the aims, the scope, the methodology, the questions used, or the sample population being surveyed.

Therefore, the European Commission initiated the European project SARTRE (Social Attitudes to Road Traffic Risk in Europe; homepage: www.attitudes-roadsafety.eu/) in 1991. A common questionnaire and study design were developed, and face-to-face interviews were conducted among a representative sample of the national adult population. Four editions of the SARTRE survey were launched $(1991,1996,2002,2010)$. In the first three editions of the SARTE project, surveys were directed only to car drivers. In the fourth edition, the target group was extended to 'powered two wheelers', pedestrians, cyclists, and users of public transport (Cestac \& Delhomme, 2012). The SARTRE4 survey in 2010, was the last large-scale measurement of social attitudes towards road traffic risk in Europe. Since then, comparable and reliable data on road safety attitudes and behavior within Europe have not been available.

In 2015, Vias institute launched the ESRA initiative (E-Survey of Road users' Attitudes; homepage: www.esranet.eu) (Torfs, Meesmann, Van den Berghe, \& Trotta, 2016), in cooperation with research institutes and road safety organizations from 25 countries. The aim of the project is: (1) to obtain, for all the countries involved, national information on opinions, self-reported behavior and attitudes with respect to road safety and related transport issues, (2) to obtain comparable road safety information across the countries involved to allow reliable international comparisons and benchmarking, and (3) to provide policy makers in the participating countries with data to support the formulation of policy measures.

The ESRA survey covers a wide range of road safety related topics, such as attitudes towards unsafe traffic behavior, selfreported (unsafe) behavior in traffic, support of road safety policy measures, crash involvement, and perceived safety feeling. The ESRA consortium opted for a web survey using internet access panels, because of the advantages with respect to timing, costs, comparability of the data, and social desirability in responses. In each participating country, a representative sample of at least 1000 adults participated in the survey. Note, that this representativeness is solely based on gender, age and regional spread of the population (based on population statistics of the United Nations: www.data.un.org). Characteristics such as educational level were not taken into account to define representativeness. The survey targeted all road user types. The field work was carried out in two waves: (1) June/July 2015, and (2) November 2016. In total, the first two waves of the first ESRA edition (ESRA1) covered almost 27,000 respondents from 25 countries across the world.

\subsection{Research questions}

The objective of this paper is to present the ESRA1 results regarding the safety attitudes of vulnerable road users. Special attention will be given to the topics road crash involvement, safety feeling, and self-reported unsafe traffic behavior with a focus on the use of headphone and lack of use of (motor)cycle helmet. These two unsafe traffic behaviors are of special inter- 
est, because (1) distraction of road users due to the use of mobile devices is a growing concern for road safety (WHO, 2011), and (2) numerous studies have shown that a bicycle helmet is an effective way of preventing head injuries (e.g., Cripton, Dressler, Stuart, Dennison, \& Richards, 2014; Olivier \& Radun, 2017; recent meta-analysis by Høye, 2018). Hence, the following research questions were addressed in this paper:

(1) Are vulnerable road users more involved in road crashes compared to car drivers?

(2) Do vulnerable road users feel less safe in traffic compared to car drivers?

(3) Which explanatory variables are associated with self-reported headphone use among pedestrians and cyclists?

(4) Which explanatory variables are associated with self-reported helmet use among cyclists and moped/motorcyclists?

\section{Methodology}

Given the focus of the ESRA project on road users' perceptions and attitudes, we opted for a self-administered questionnaire. The ESRA1 survey was designed as a web survey using access panels. Two Belgian market research agencies (iVOX \& GfK) organized the field work under the supervision of Vias institute. The adopted approach has some advantages compared to other survey modes especially given the international context of the study: (1) self-administered web surveys are less prone to social desirability in responses compared to interviewer-administered surveys, and (2) they also have some practical advantages such as the length of the survey, timing, and costs (Baker et al., 2010; De Leeuw, Hox, \& Dillman, 2008; Goldenbeld \& de Craen, 2013). It should be recognized, however, that internet penetration varies between countries. Consequently, coverage and sampling may be sub-optimal (in all ESRA1 countries internet penetration was at least $66 \%$ in 2015 ; World bank, n.d.). Therefore, the contracted market research agencies are members of ESOMAR, which defined standards for recruiting online panels to minimise selection bias. In brief, having a uniform sampling method, an identical questionnaire, and uniform programming of this questionnaire allow ESRA1 results to be comparable among the participating countries.

Fig. 1 shows the geographic coverage of the survey. The target population was the adult population $(\geq 18 \mathrm{y})$ of each country. The targeted number of respondents was 1000 in each country. At least 600 respondents should be regular car drivers (i.e., having a car driving license and driven at least $1500 \mathrm{~km}$ with a car or a van in the last 6 months). If needed, the sample of 1000 respondents could be extended in order to fulfill both requirements of 600 regular car drivers and a national representative sample. The market research agencies used quota for age and gender (interlaced), and monitored a geographical distribution. The total sample size consisted of 26,856 road users from 25 countries.

In view of comparability, not just between the countries, but also with surveys that have been conducted in the past, almost all questions of the ESRA1 survey were based on, and often identical to questions previously used and validated in Belgian (Belgian Road Safety Institute, 2015; Meesmann, Boets, \& Silverans, 2014), European (Cestac \& Delhomme, 2012),
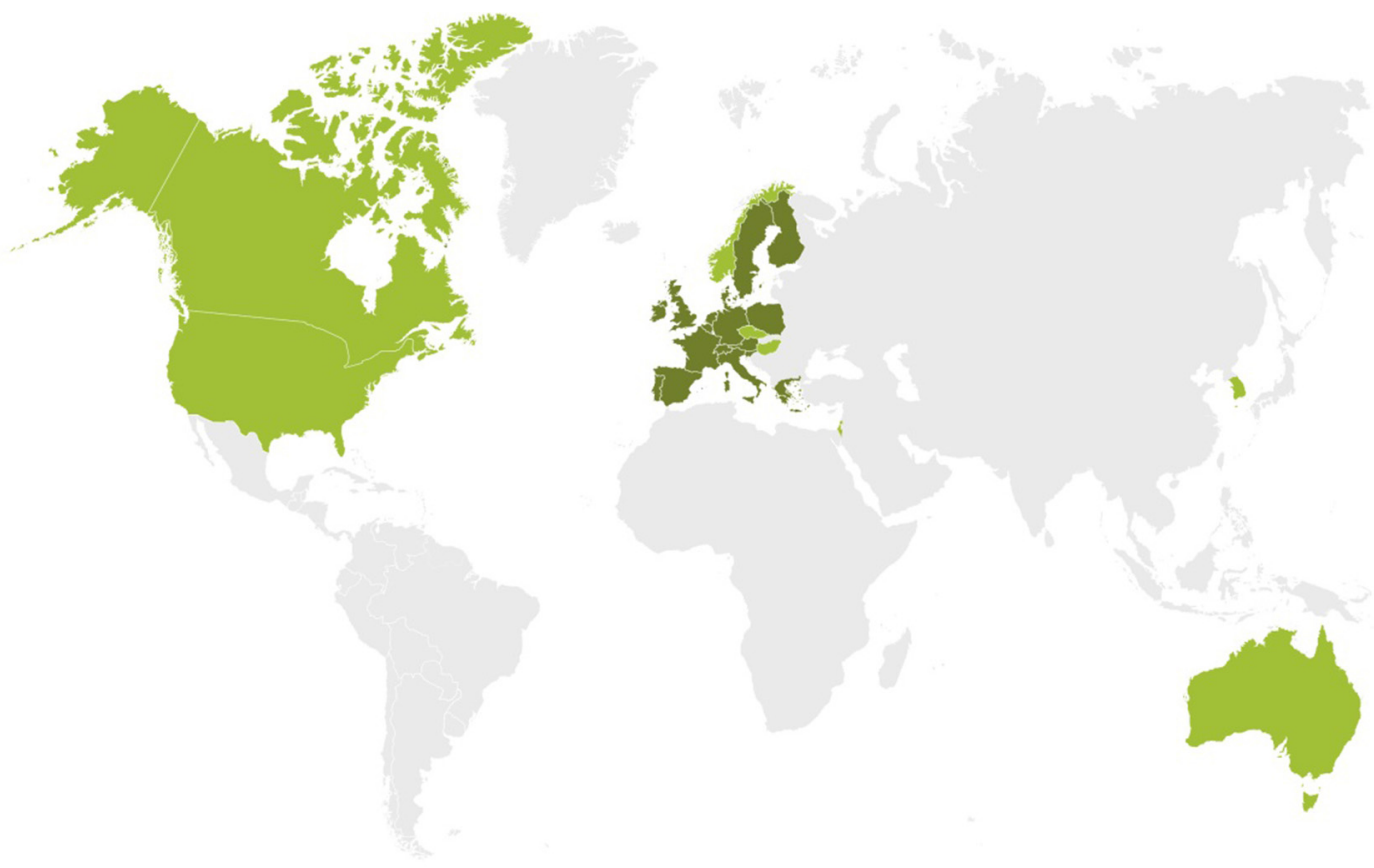

Fig. 1. Geographical coverage of the ESRA1 survey. 
and American (AAA Foundation for Traffic Safety, 2016) surveys. The survey covered diverse themes, such as attitudes towards unsafe traffic behavior, self-reported (unsafe) behavior in traffic, and the feeling of unsafety as a road user (all information on the questionnaire is available on www.esranet.eu; questionnaire is included as appendix in Torfs et al., 2016). Given that the estimated maximum duration for completing the online survey was set to $20 \mathrm{~min}$, not all themes could be covered in the same depth. Moreover, the questionnaire was produced in 30 different language versions. Data collection took place in two phases: the first phase of field work took place in June and July 2015 (17 countries) and the second phase in September until December of 2016 (8 countries).

\section{Analysis and results}

In the first part, we report on the crash involvement and safety feeling of vulnerable road users compared to car drivers. The following questions were studied: (1) Are vulnerable road users more involved in road crashes compared to car drivers? and (2) Do vulnerable road users feel less safe in traffic compared to car drivers? In the second part, we focus on the selfreported unsafe traffic behavior of pedestrians, cyclists, and moped/motorcyclists. SPSS was used for all analyses (IBM Corp, 2013).

\subsection{Road crash involvement and safety feeling}

The Chi-square test was used to study whether the involvement in road crashes differs between vulnerable road users and car drivers. Respondents were categorized based on their most frequently used transport mode to guarantee independence between the vulnerable road users and car drivers. Also, a weighting was applied to cancel out differences in age and gender distributions between the two road user groups. Results showed that $7 \%$ of the vulnerable road users in the ESRA1 population were involved in a road crash in the past three months compared to $5.6 \%$ of the car drivers $\left(\chi_{(\mathrm{df}=1)}^{2}=10.642\right.$; $\mathrm{p}=.001$ ). No further analyses (e.g., country comparisons) were done, because the size of the (sub)samples were too small to guarantee reliable results.

These results are in accordance with road crash statistics (ETSC, 2003; Mayou \& Bryant, 2003) and the question arises whether vulnerable road users also feel less safe in traffic. Respondents were again categorized based on their most frequently used transport mode; a weighting was applied to cancel out differences in age and gender distributions between the two road user groups. Safety feeling was measured on an 11 -point scale from $(0=$ very unsafe to $10=$ very safe). The Mann-Whitney $U$ test was used to study whether vulnerable road users feel less safe compared to car drivers. Results showed that on average vulnerable road users (VRU) in the ESRA1 population feel slightly less safe compared to car drivers $\left(\mathrm{M}_{\mathrm{VRU}}=6.8 \mathrm{SD}_{\mathrm{VRU}}=2.5 ; \mathrm{M}_{\mathrm{CAR}}=7.2 \mathrm{SD}_{\mathrm{CAR}}=2.1 ; \mathrm{p}<.001\right)$. Subsequently, the safety feeling of different types of vulnerable road users was also compared; the Kruskall-Wallis test was used for this purpose. Results are presented in Table 1 and show that pedestrians feel safer in traffic compared to other types of vulnerable road users $\left(\chi_{(\mathrm{df}=4)}^{2}=200.307 ; \mathrm{p}<.001\right)$.

\subsection{Self-reported unsafe behavior}

Binary logistic regression models were used to investigate the association between several explanatory variables and selfreported behavior of vulnerable road users. We focused on two types of unsafe traffic behavior: (1) headphone use by pedestrians and cyclists and (2) no helmet use by cyclists and moped drivers/motorcyclists. Respondents were categorized as a particular type of vulnerable road user (e.g., pedestrian) if they have used this particular mode of transportation in the past 12 months (i.e., at least once). In each model, the outcome is a binary variable indicating the absence $(0=$ never $)$ or presence ( $1=$ at least once) of self-reported behaviors in the past 12 months. Personal characteristics such as gender, age, and educational level were included as explanatory factors together with support for road safety policy measures and safety feeling as a vulnerable road user. Respondent's nationality was also included in the models in order to explore similarities between the participating countries while controlling for other factors. Odds ratios (and their 95\% Confidence Intervals) were used to

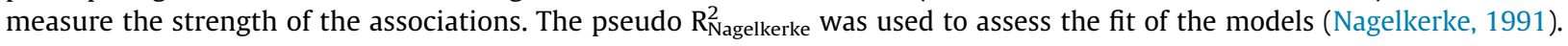

Table 1

Average safety feeling of different types of vulnerable road users.

\begin{tabular}{lll}
\hline Type of vulnerable road user & \multicolumn{2}{l}{ Safety feeling } \\
\cline { 2 - 3 } & Mean & SD \\
\hline Pedestrian & 7.0 & 2.4 \\
e-bike & 6.1 & 2.9 \\
Cyclist & 6.2 & 2.5 \\
Moped & 5.8 & 2.6 \\
Motorcyclist & 5.4 & 3.0 \\
\hline
\end{tabular}

Note. Safety feeling was measured on an 11-point scale from $0=$ very unsafe to $10=$ very safe. 
Table 2 shows the results of the logistic regression models for the use of headphones by pedestrians (Model 1 ) and by cyclists (Model 2). The odds of listening to music through a headphone as a pedestrian for women are $11 \%(\mathrm{OR}=0.89)$ less compared to men; this means that women were less likely to report listening to music through headphones as pedestrians. Moreover, the odds of listening to music through a headphone as a pedestrian decreased with increasing age (by 64\% $(\mathrm{OR}=0.36)$ for pedestrians aged $35-54 \mathrm{y}$ and $87 \%(\mathrm{OR}=0.13)$ for pedestrians $55 \mathrm{y}$ or older $)$. In other words, predominantly young pedestrians (aged 18-34y) reported listening to music through headphones or earbuds. Similar trends were observed for cyclists (see Table 2). Additionally, pedestrians and cyclists who support a ban of using headphones (or earbuds) by pedestrians and cyclists were less likely to report using them ( $\mathrm{OR}=0.27$ and $\mathrm{OR}=0.32$, respectively). Furthermore, cyclists with at least a master's degree were also less likely to listen to music through headphones (decrease of $27 \%$ compared to respondents with only primary education). This trend was not observed for pedestrians. Finally, pedestrians feeling unsafe and rather safe in traffic were more likely (increases of about 20-35\%) to report having listened to music through headphones in the past 12 months compared to those feeling very safe.

Table 3 shows the results of the logistic regression models for the non-use of helmets by cyclists (Model 3) and moped/motorcyclists (Model 4). The odds of not wearing a helmet as a cyclist for women and men were alike. Also, no association of educational level was found on reporting helmet use by cyclists. The same trends were observed for moped/motorcyclists. However, the odds of not wearing a helmet as a cyclist decrease with increasing age (by $29 \%$ (OR = 0.71) for cyclists aged 35$54 \mathrm{y}$ and $33 \%(\mathrm{OR}=0.67)$ for cyclists $55 \mathrm{y}$ or older). In other words, predominantly young cyclists (aged 18-34y) reported not wearing a helmet. For moped/motorcyclists, drivers aged 35-54y were more likely to report wearing a helmet compared to younger drivers $(\mathrm{OR}=0.69)$. Furthermore, no association was found between the safety feeling of moped/motorcyclists and their self-reported helmet use. However, the odds of not wearing a helmet as a cyclist decreased by $23 \%$ (OR = 0.77 ) for cyclists who feel very unsafe in traffic compared to those who feel very safe. In other words, cyclists who feel very unsafe in traffic reported more often to wear a helmet when cycling. Finally, cyclists who support obligatory use of a helmet by all cyclists were more likely to wear a helmet themselves $(\mathrm{OR}=0.19)$.

Table 4 shows the odds ratio of each country for the two models presented in Table 2. The country closest to the ESRA average was chosen as the reference category in each model. To identify groups of countries with similar likelihoods of self-reported behaviors, they were grouped according to the odds ratios (different colors indicating significant differences in Table 4): 0.80 or lower (green); from 0.81 to 1.19 (white); from 1.20 to 1.99 (yellow); 2.00 or higher (orange). Belgium, Czech Republic, Hungary, and the Netherlands are the countries where pedestrians were the least likely to listen to music through headphones or earbuds compared to the reference countries. On the other hand, Korean pedestrians had the highest odds. Korean cyclists had also the highest odds of listening to music through headphones, together with cyclists in Australia and the United States of America. Conversely, Austria, Belgium, Switzerland, Czech Republic, and Hungary are the countries where cyclists were the least likely to listen to music through headphones or earbuds.

Table 4 also shows the odds ratio of each country for the two models presented in Table 3. Results revealed that Australia, Ireland, Israel and the United Kingdom are the countries where cyclists were the most likely to wear a helmet compared to the reference countries. On the other hand, Hungarian cyclists had the highest odds for not wearing a helmet. Regarding the use of motorcycle helmet only Portugal had significant lower odds for not wearing a helmet compared to all other countries.

Table 2

Logistic regression models for listening to music through headphones (or earbuds) by pedestrians and cyclists.

\begin{tabular}{|c|c|c|}
\hline \multirow[t]{2}{*}{ Factors (reference category) } & \multicolumn{2}{|c|}{$\begin{array}{l}\text { Dependent variable: self-reported unsafe behavior } \\
(0=\text { never; } 1 \text { = at least once) listening to music through } \\
\text { headphones (earbuds) }\end{array}$} \\
\hline & by pedestrians (Model 1 ) & by cyclists (Model 2) \\
\hline & Odds Ratio (CI95\%) & Odds Ratio (CI95\%) \\
\hline \multicolumn{3}{|l|}{ Gender (Male) } \\
\hline Female & $0.893^{* *}(0.836-0.955)$ & $0.714^{* *}(0.649-0.787)$ \\
\hline \multicolumn{3}{|l|}{ Age $(18-34 y)$} \\
\hline $35-54 y$ & $0.358^{* *}(0.332-0.386)$ & $0.446^{* *}(0.402-0.494)$ \\
\hline$\geq 55 y$ & $0.128^{* *}(0.116-0.141)$ & $0.165^{* *}(0.142-0.192)$ \\
\hline \multicolumn{3}{|l|}{ Educational level (Primary education or none) } \\
\hline Secondary education & $0.939(0.786-1.122)$ & $0.851(0.665-1.088)$ \\
\hline Bachelor's degree or similar & $0.970(0.810-1.163)$ & $0.798(0.621-1.025)$ \\
\hline Master's degree or higher & $0.915(0.758-1.104)$ & $0.734^{*}(0.566-0.952)$ \\
\hline \multicolumn{3}{|l|}{ Support of road safety measures (Oppose/no opinion) } \\
\hline A ban of using headphones (or earbuds) by pedestrians and cyclists (Support) & $0.273^{* *}(0.255-0.292)$ & $0.324^{* *}(0.293-0.358)$ \\
\hline \multicolumn{3}{|l|}{ Safety feeling (Very safe) } \\
\hline Rather safe & $1.196^{* *}(1.110-1.288)$ & $1.029(0.920-1.150)$ \\
\hline Rather unsafe & $1.349^{* *}(1.200-1.516)$ & $1.077(0.923-1.257)$ \\
\hline Very unsafe & $1.121(0.963-1.305)$ & $0.907(0.759-1.084)$ \\
\hline $\mathrm{R}^{2}$ Nagelkerke $\left(\mathrm{pseudo} \mathrm{R}^{2}\right.$ ) & 0.309 & 0.247 \\
\hline
\end{tabular}

Note. (1) ${ }^{*} \mathrm{p}<.05 ;{ }^{* *} \mathrm{p}<.01$ (2) The factor safety feeling was categorized as follows: 0-2 (very unsafe); 3-4 (rather unsafe); 5-7 (rather safe); 8-10 (very safe).

(3) The factor nationality of both models is presented in Table 4. 
Table 3

Logistic regression models for helmet use by cyclists and moped/motorcyclists.

\begin{tabular}{|c|c|c|}
\hline \multirow[t]{2}{*}{ Factors (reference category) } & \multicolumn{2}{|c|}{$\begin{array}{l}\text { Dependent variable: self-reported unsafe behavior }(0=\text { never; } 1=\text { at least } \\
\text { once) not wearing a helmet }\end{array}$} \\
\hline & by cyclists (Model 3) & by moped/motorcyclists (Model 4) \\
\hline & Odds Ratio (CI 95\%) & Odds Ratio (CI 95\%) \\
\hline \multicolumn{3}{|l|}{ Gender (Male) } \\
\hline Female & $1.081(0.972-1.202)$ & $0.798(0.595-1.071)$ \\
\hline \multicolumn{3}{|l|}{ Age (18-34y) } \\
\hline $35-54 y$ & $0.714^{* *}(0.631-0.808)$ & $0.686^{*}(0.515-0.914)$ \\
\hline$\geq 55 y$ & $0.673^{* *}(0.583-0.778)$ & $0.785(0.506-1.218)$ \\
\hline \multicolumn{3}{|l|}{ Educational level (Primary education or none) } \\
\hline Secondary education & $1.050(0.800-1.378)$ & $0.976(0.451-2.116)$ \\
\hline Bachelor's degree or similar & $1.002(0.760-1.320)$ & $0.771(0.354-1.678)$ \\
\hline Master's degree or higher & $0.859(0.647-1.141)$ & $0.741(0.336-1.632)$ \\
\hline \multicolumn{3}{|l|}{ Support of road safety measures (Oppose/no opinion) } \\
\hline Obligatory use of a helmet by all cyclists (Support) & $0.194^{* *}(0.173-0.219)$ & - \\
\hline \multicolumn{3}{|l|}{ Safety feeling (Very safe) } \\
\hline Rather safe & $0.974(0.858-1.106)$ & $1.271(0.911-1.773)$ \\
\hline Rather unsafe & $0.962(0.811-1.142)$ & $1.130(0.737-1.733)$ \\
\hline Very unsafe & $0.768^{* * *}(0.640-0.922)$ & $0.679(0.441-1.044)$ \\
\hline $\mathrm{R}^{2}$ Nagelkerke (pseudo $\mathrm{R}^{2}$ ) & 0.210 & 0.071 \\
\hline
\end{tabular}

Note. (1) ${ }^{*} \mathrm{p}<.05 ;{ }^{* *} \mathrm{p}<.01$ (2) The factor safety feeling was categorized as follows: 0-2 (very unsafe); 3-4 (rather unsafe); 5-7 (rather safe); 8-10 (very safe). (3) The factor nationality of models 3 and 4 is presented in Table 4.

\section{Discussion}

The ESRA1 survey studied three important aspects of vulnerable road users' traffic behavior. Firstly, results revealed that self-reported crash involvement was higher for vulnerable road users compared to car drivers in the participating countries. These results are in accordance with road crash statistics (ETSC, 2003; Mayou \& Bryant, 2003). Worldwide, vulnerable road users contribute to almost half of the total road traffic deaths (WHO, 2009). According to the European Transport Safety Council, the death risk travelled varies between 5.4 and 13.8 deaths per 100 million person kilometers for vulnerable road users compared to 0.7 for car drivers in Europe (ETSC, 2003). Not surprisingly, the ESRA1 results showed that vulnerable road users also feel less safe compared to car drivers. A similar result was found in SARTRE4 (Cestac \& Delhomme, 2012) where a related question, i.e. perceived danger of transport modes, was included.

Secondly, results on distraction in traffic by vulnerable road users showed that women were less likely to report listening to music through headphones. Moreover, mostly young respondents (aged $18-34 \mathrm{y}$ ) reported listening to music through headphones or earbuds while walking or cycling. Additionally, pedestrians and cyclists who support a ban of using headphones (or earbuds) by pedestrians and cyclists were less likely to report using them. Finally, pedestrians feeling very safe were less likely to report having listened to music through headphones in the past 12 months. The use of mobile devices such as mobile phones and portable music players in traffic is a growing concern for road safety, because they can distract road users in several manners such as physically, visually, cognitive, or auditory (de Waard, Edlinger, \& Brookhuis, 2011; de Waard, Schepers, Ormel, \& Brookhuis, 2010; WHO, 2011). For example, Goldenbeld and colleagues (Goldenbeld, Houtenbos, Ehlers, \& de Waard, 2012) studied the use and the associated risk of portable electronic devices while cycling and found that listening to music results in cyclists missing more auditory information necessary for safe participation in traffic. These negative effects were even magnified when using earbuds and when listening at high volume or fast tempo. Moreover, music can also influence road users' emotions (so-called mood effects (Dibben \& Williamson, 2007; Meesmann, Boets, \& Tant, 2009)).

Thirdly, ESRA1 investigated helmet use by cyclists and motorcyclists, because several studies have shown that a bicycle helmet is an effective way of preventing head injury (see meta-analyses Attewell, Glase, \& McFadden, 2001; Olivier \& Creighton, 2017; Høye, 2018). Despite their effectiveness, the use of a bicycle helmet seems to depend mostly on a cyclist's motivation rather than other factors such as exposure, ecological, or financial aspects (Jacques, 1994). The results of ESRA1 revealed no association of gender and educational level on reporting helmet use by cyclists or moped/motorcyclists. Also, no association was found between the safety feeling of moped/motorcyclists and their self-reported helmet use. However, cyclists who feel very unsafe in traffic reported more often to wear a helmet when cycling. Likewise, cyclists who support obligatory use of a helmet by all cyclists were more likely to wear a helmet themselves. Finally, mostly young cyclists (aged $18-34 y$ ) reported not wearing a helmet; this is in accordance with a recent study in the U.S.A. that found about $60 \%$ of the adult cyclists aged 18-29y never wore a helmet when cycling (Jewett, Beck, Taylor, \& Baldwin, 2016). For moped/motorcyclists, drivers aged 35-54y were more likely to report wearing a helmet compared to younger drivers.

Questions for more in-depth research arise from the results discussed here. For instance: What is the causality between one's safety feeling and their use of mobile devices in traffic? Furthermore, the differences found between countries might be explained by differences in legislation (e.g. obligatory helmet use by cyclists in Australia, but not in most other countries, 
Table 4

Logistic regression models for using headphones as pedestrian or cyclist and helmet use by cyclists and moped/motorcyclists: effect of the countries.

\begin{tabular}{|c|c|c|c|c|}
\hline \multirow[b]{2}{*}{ Country } & \multicolumn{4}{|c|}{ Dependent variable: self-reported unsafe behavior $(0=$ never; $1=$ at least once $)$} \\
\hline & $\begin{array}{c}\text { Model } 1 \\
\text { listening to music } \\
\text { through headphones } \\
\text { (or earbuds) by } \\
\text { pedestrians }\end{array}$ & $\begin{array}{c}\text { Model } 2 \\
\text { listening to music } \\
\text { through headphones } \\
\text { (or earbuds) by } \\
\text { cyclists }\end{array}$ & $\begin{array}{c}\text { Model } 3 \\
\text { not wearing a helmet } \\
\text { by cyclists }\end{array}$ & $\begin{array}{c}\text { Model } 4 \\
\text { not wearing a helmet } \\
\text { by } \\
\text { moped/motorcyclists }\end{array}$ \\
\hline & Odds Ratio (CI 95\%) & Odds Ratio (CI 95\%) & Odds Ratio (CI 95\%) & Odds Ratio (CI 95\%) \\
\hline Austria & $.79(.62-1)$ & $.49 * *(.35-.68)$ & $.95(.65-1.38)$ & $1.52(.45-5.19)$ \\
\hline Australia & $\mathbf{1 . 0 7}(.84-1.36)$ & $2.01 * *(1.38-2.90)$ & $.25 * *(.17-.38)$ & $1.31(.42-4.04)$ \\
\hline Belgium & $.47 * *(.37-.60)$ & $.68 *(.50-.93)$ & $1.80 * *(1.19-2.73)$ & $1.56(.34-7.25)$ \\
\hline Canada & $1.51 * *(1.21-1.89)$ & $1.28(.90-1.81)$ & $.37(.25-.54)$ & $.68(.21-2.19)$ \\
\hline Switzerland & $.95(.75-1.20)$ & $.67 *(.48-.92)$ & $.73(.50-1.06)$ & $1.06(.34-3.25)$ \\
\hline $\begin{array}{l}\text { Czech } \\
\text { Republic }\end{array}$ & $.60 * *(.48-.74)$ & $.52 * *(.39-.71)$ & $.84(.59-1.19)$ & $1.11(.36-3.39)$ \\
\hline Germany & $.91(.72-1.15)$ & $.79(.59-1.06)$ & $1.42(.97-2.08)$ & $.85(.29-2.49)$ \\
\hline Denmark & $.88(.71-1.11)$ & $\mathbf{1 . 1 5}(.88-1.51)$ & $\mathbf{1 . 0 2}(.72-1.45)$ & $1.40(.41-4.80)$ \\
\hline Greece & $1.40 * *(1.13-1.74)$ & $1.52 *(1.04-2.21)$ & $1.55(.97-2.49)$ & $\mathbf{1 . 8 7}(.49-7.12)$ \\
\hline Spain & $\mathbf{1 . 8 3} * *(1.47-2.28)$ & $.99(.73-1.34)$ & $.80(.55-1.15)$ & $.71(.25-1.98)$ \\
\hline Finland & 1 (Reference) & 1 (Reference) & $\mathbf{1 . 1 7}(.82-1.68)$ & $1.59(.48-5.24)$ \\
\hline France & $.83(.65-1.05)$ & $.82(.59-1.15)$ & 1 (Reference) & $.85(.29-2.45)$ \\
\hline Hungary & $.58 * *(.47-.72)$ & $.57 * *(.45-.77)$ & $2.11 * *(1.42-3.14)$ & $1.02(.31-3.41)$ \\
\hline Ireland & $\mathbf{1 . 5 6}(1.28-1.95)$ & $.92(.65-1.28)$ & $.64 *(.44-.94)$ & $2.01(.35-11.58)$ \\
\hline Israel & $\mathbf{1 . 6 1 * *}(1.31-1.99)$ & $.98(.70-1.36)$ & $.63 *(.43-.93)$ & $.74(.20-2.69)$ \\
\hline Italy & $1.23(.95-1.60)$ & $1.65 *(1.11-2.46)$ & $1.16(.74-1.81)$ & $.57(.19-1.76)$ \\
\hline $\begin{array}{l}\text { Republic of } \\
\text { Korea }\end{array}$ & $\mathbf{2 . 9 3} * *(2.33-3.69)$ & $4.53 * *(3.27-6.28)$ & $\mathbf{1 . 3 2}(.89-1.98)$ & $1.17(.38-3.64)$ \\
\hline Netherlands & $.70 * *(.56-.88)$ & $1.16(.89-1.52)$ & $\mathbf{1 . 1 9}(.81-1.74)$ & $\mathbf{1 . 4 0}(.48-4.10)$ \\
\hline Norway & $1.59 * *(1.27-1.99)$ & $\mathbf{1 . 5 3} * *(1.15-2.05)$ & $.86(.60-1.23)$ & $.77(.26-2.27)$ \\
\hline Poland & $\mathbf{1 . 1 2}(.90-1.39)$ & $1.12(.86-1.46)$ & $1.64 * *(1.14-2.35)$ & $.80(.28-2.30)$ \\
\hline Portugal & $.93(.75-1.16)$ & $.84(.59-1.20)$ & $.76(.51-1.12)$ & $.30 *(.10-.92)$ \\
\hline Sweden & $\mathbf{1 . 4 6 * *}(1.19-1.79)$ & $1.25(.95-1.64)$ & $\mathbf{1 . 3 8}(.97-1.98)$ & $1.44(.46-4.52)$ \\
\hline Slovenia & $.69 * *(.50-.89)$ & $1.04(.72-1.49)$ & $1.33(.838-2.113)$ & 1 (Reference) \\
\hline UK & $\mathbf{1 . 1 1}(.89-1.39)$ & $.90(.62-1.31)$ & $.48 * *(.32-.70)$ & $.45(.13-1.52)$ \\
\hline US & $1.73 * *(1.36-2.18)$ & $2.72 * *(1.88-3.93)$ & $.66(.44-1.01)$ & $.82(.28-2.40)$ \\
\hline
\end{tabular}

Notes. (1) ${ }^{*} \mathrm{p}<.05 ;{ }^{* *} \mathrm{p}<.01$ (2) Colors in relation to the odds ratios indicating significant differences compared to the reference country: 0.80 or lower (green); from 0.81 to 1.19 (white); from 1.20 to 1.99 (yellow); 2.00 or higher (orange).

IRTAD). Note, that the current results are based solely on individual data. Through data-linking, individual survey data and national characteristics (e.g. economic development, legislation) can be combined in a common statically model (example of multilevel analysis combining national data with individual SARTE4 survey data: Meesmann, Martensen, \& Dupont, 2015). Therefore, the individual data of the next ESRA survey (ESRA2), will be supplemented by national contextual information/data, to facilitate more in-depth analyses and interpretation of the available data.

The ESRA1 survey offers a unique database and provides policy makers valuable insights into public perception of road safety. This database also provides the opportunity to compare attitudes and self-reported safe and unsafe traffic behaviors in different countries. Although the results of ESRA1 can form the basis for benchmarking road safety culture in the participating countries, lessons for upcoming editions can be learned from this first one.

Firstly, having a standardized methodology and sampling procedure in all participating countries is essential to obtain fully comparable and reliable data (De Leeuw, Hox, \& Dillman, 2008). Although this was clearly anticipated in ESRA1 a few issues arose, e.g. different numbers of age categories (three vs. six) were used during sampling (see Torfs et al. (2016) for more details). Moreover, a selection bias due to voluntary participation in online panels cannot be completely avoided (e.g. differences in educational level or socio-economic status). To minimize this effect, ESOMAR defined standards for recruiting online panels. The market research agencies contracted in the ESRA project, all adhere to these standards. Furthermore, the questionnaire of the ESRA2 survey will include additional variables which can be used to control for these potentially biased characteristics of the sample. 
Secondly, survey research is fraught with general response tendencies and biases, and this is especially true in crossnational studies (Lajunen, Corry, Summala, \& Hartley, 1997; Tellis \& Chandrasekaran, 2010). These biases might lead to erroneous conclusions (i.e., confusing differences in socially desirable responding with genuine differences in the measured trait). Therefore, the ESRA2 survey will include a social desirability scale. Additionally, if possible, results should be validated based on external sources.

\section{Conclusions}

The results of ESRA1 give valuable insights into public perception of road safety; they provide the opportunity to compare attitudes and self-reported safe and unsafe traffic behaviors in different countries. The intention is to repeat this initiative on a triennial basis. Furthermore, by retaining a core set of questions in every survey, a time series of road safety performance indicators can be developed.

\section{Acknowledgments}

As coordinator of the ESRA project, the authors would like to thank all 25 participating organizations for their enthusiastic commitment, flexibility, and cooperative attitude. This research did not receive any specific grant from funding agencies in the public, commercial, or not-for-profit sectors, but was funded by the partners' own resources. The authors also thank Huong Nguyen for reviewing this paper with respect to US English.

\section{Appendix A. Supplementary material}

Supplementary data to this article can be found online at https://doi.org/10.1016/j.trf.2019.04.001.

\section{References}

AAA Foundation for Traffic Safety (2016). 2015 Traffic Safety Culture Index. Washington DC. Retrieved from https://aaafoundation.org/wp-content/uploads/ 2016/02/2015TrafficSafetyCultureIndexReport.pdf.

Ajzen, I. (1991). The theory of planned behavior. Organizational Behavior and Human Decision Processes, 50(2), 179-211. https://doi.org/10.1016/0749-5978 (91) $90020-\mathrm{T}$

Attewell, R. G., Glase, K., \& McFadden, M. (2001). Bicycle helmet efficacy: A meta-analysis. Accident Analysis and Prevention, 33(3), 345-352. https://doi.org/ 10.1016/S0001-4575(00)00048-8.

Baker, R., Blumberg, S. J., Brick, J. M., Couper, M. P., Courtright, M., Dennis, J. M., ... Baker, R. (2010). AAPOR report on online panels. Public Opinion Quarterly, 74(4), 711-781. https://doi.org/10.1093/poq/nfq048.

Belgian Road Safety Institute (2015). Nationale VerkeersONVeiligheidsenquête 2014 (NVOV). Brussels: Belgian Road Safety Institute. Retrieved from http:// enquetebivv.be/files/folder_nl.pdf.

Cestac, J., \& Delhomme, P. (2012). European road users' risk perception and mobility The SARTRE 4 survey. Lyon. Retrieved from http://www.attitudesroadsafety.eu/index.php?eID=tx_nawsecuredl\&u=0\&file=uploads/media/Sartre-4-report.pdf\&t=1518086356\&hash= 7469ce049fc6f9070015dec681334e5b.

Cripton, P. A., Dressler, D. M., Stuart, C. A., Dennison, C. R., \& Richards, D. (2014). Bicycle helmets are highly effective at preventing head injury during head impact: Head-form accelerations and injury criteria for helmeted and unhelmeted impacts. Accident Analysis \& Prevention, 70, 1-7. https://doi.org/ 10.1016/j.aap.2014.02.016.

De Leeuw, E. D., Hox, J. J., \& Dillman, D. A. (2008). In E. D. De Leeuw, J. J. Hox, \& D. A. Dillman (Eds.), International handbook of survey methodology, 1st ed. New York: Psychology Press. Taylor \& Francis Group.

de Waard, D., Edlinger, K., \& Brookhuis, K. (2011). Effects of listening to music, and of using a handheld and handsfree telephone on cycling behaviour. Transportation Research Part F: Traffic Psychology and Behaviour, 14(6), 626-637. https://doi.org/10.1016/J.TRF.2011.07.001.

de Waard, D., Schepers, P., Ormel, W., \& Brookhuis, K. (2010). Mobile phone use while cycling: Incidence and effects on behaviour and safety. Ergonomics, 53 (1), 30-42. https://doi.org/10.1080/00140130903381180.

Dibben, N., \& Williamson, V. J. (2007). An exploratory survey of in-vehicle music listening. Psychology of Music, 35(4), 571-589. https://doi.org/10.1177/ 0305735607079725.

ETSC (2003). Transport safety performance in the EU. A statistical overview. Brussels: European Transport Safety Council. Retrieved from http://archive.etsc. eu/documents/statoverv.pdf.

ETSC (2015). PIN Flash Report 29, Making walking and cycling on Europe's roads safer. Brussels: European Transport Safety Council. Retrieved from http:// etsc.eu/wp-content/uploads/etsc_pin_flash_29_walking_cycling_safer.pdf.

Goldenbeld, C., \& de Craen, S. (2013). The comparison of road safety survey answers between web-panel and face-to-face; Dutch results of SARTRE-4 survey. Journal of Safety Research, 46, 13-20. https://doi.org/10.1016/j.jsr.2013.03.004.

Goldenbeld, C., Houtenbos, M., Ehlers, E., \& de Waard, D. (2012). The use and risk of portable electronic devices while cycling among different age groups. Journal of Safety Research, 43(1), 1-8. https://doi.org/10.1016/j.jsr.2011.08.007.

Høye (2018). Bicycle helmets - To wear or not to wear? A meta-analyses of the effects of bicycle helmets on injuries. Accident Analysis \& Prevention, 117, 85-97.

IBM Corp (2013). IBM SPSS Statistics for Windows, Version 22.0. Armonk, NY: IBM Corp.

Jacques, L. B. (1994). Rates of bicycle helmet use in an affluent Michigan County Retrieved from. Public Health Reports, 109(2), 296-301 https://www.ncbi. nlm.nih.gov/pmc/articles/PMC1403484/pdf/pubhealthrep00061-0146.pdf.

Jewett, A., Beck, L. F., Taylor, C., \& Baldwin, G. (2016). Bicycle helmet use among persons 5 years and older in the United States, 2012. Journal of Safety Research, 59, 1-7. https://doi.org/10.1016/j.jsr.2016.09.001.

Lajunen, T., Corry, A., Summala, H., \& Hartley, L. (1997). Impression management and self-deception in traffic behaviour inventories. Personality and Individual Differences, 22(3), 341-353. https://doi.org/10.1016/S0191-8869(96)00221-8.

Mayou, R., \& Bryant, B. (2003). Consequences of road traffic accidents for different types of road user. Injury, 34(3), 197-202. https://doi.org/10.1016/S00201383(02)00285-1. 
Meesmann, U., Boets, S., \& Silverans, P. (2014). Appendix Methodology \& Questionnaire. Results of the BIVV/IBSR three-yearly road safety attitude survey. Brussels: Belgian Road Safety Institute. Retrieved from http://www.vias.be/publications/BijlageMethodologieenvragenlijst/AppendixMethodology\& Questionnaire-ResultsoftheBIVV-IBSRthree-yearlyroadsafetyattitudesurvey.pdf.

Meesmann, U., Boets, S., \& Tant, M. (2009). MP3 players and traffic safety: “State of the Art.” Brussels: Belgian Road Safety Institute. Retrieved from http:// www.vias.be/publications/MP3playersandtrafficsafetyStateoftheart/MP3playersandtrafficsafetyStateoftheart.pdf.

Meesmann, U., Martensen, H., \& Dupont, E. (2015). Impact of alcohol checks and social norm on driving under the influence of alcohol (DUI). Accident Analysis and Prevention, 80, 251-261.

Nagelkerke, N. J. D. (1991). A note on a general definition of the coefficient of determination. Biometrika, 78(3), 691-692. https://doi.org/10.1093/biomet/ 78.3.691.

OCDE/OECD (1998). Safety of vulnerable road users. Paris: Organisation for Economic Co-Operation and Development (OECD). Retrieved from http://www. oecd.org/sti/transport/roadtransportresearch/2103492.pdf.

Olivier, J., \& Creighton, P. (2017). Bicycle injuries and helmet use: A systematic review and meta-analysis. International Journal of Epidemiology, 46(1), 278-292. https://doi.org/10.1093/ije/dyw153.

Olivier, J., \& Radun, I. (2017). Bicycle helmet effectiveness is not overstated. Traffic Injury Prevention, 18(7), 755-760. https://doi.org/10.1080/ 15389588.2017 .1298748$.

Rogers, R. W. (1975). A protection motivation theory of fear appeals and attitude change. The Journal of Psychology, 91(1), 93-114. https://doi.org/10.1080/ 00223980.1975 .9915803$.

Rosenstock, I. M. (1974). The health belief model and preventive health behavior. Health Education Monographs, 2(4), 354-386. https://doi.org/10.1177/ 109019817400200405.

SWOV (2012). SWOV Fact sheet Vulnerable road users. Leidschendam: Stichting Wetenschappelijk Onderzoek Verkeersveiligheid SWOV. Retrieved from https://www.swov.nl/sites/default/files/publicaties/gearchiveerde-factsheet/uk/fs_vulnerable_road_users_archived.pdf

Tellis, G. J., \& Chandrasekaran, D. (2010). Extent and impact of response biases in cross-national survey research. International Journal of Research in Marketing, 27(4), 329-341. https://doi.org/10.1016/J.IJRESMAR.2010.08.003.

Torfs, K., Meesmann, U., Van den Berghe, W., \& Trotta, M. (2016). Synthesis of the main findings from the ESRA survey in 17 countries Retrieved from. Brussels: Belgian Road Safety Institute www.esranet.eu.

United Nations (2010). Improving global road safety, Pub. L. No. A/RES/64/255 (2010). Retrieved from http://undocs.org/A/RES/64/255.

Van Kampen, L. T. B. (2000). De invloed van voertuigmassa, voertuig- type en type botsing op de ernst van letsel. Leidschendam: Stichting Wetenschappelijk Onderzoek Verkeersveiligheid SWOV. Retrieved from https://www.swov.nl/sites/default/files/publicaties/rapport/r-2000-10.pdf.

WHO (2009). Global status report on road safety: Time for action. World Health Organization. Geneva: WHO Press. Retrieved from www.who.int/violence injury_prevention/road_safety_status/2009.

WHO (2011). Mobile phone use: A growing problem of driver distraction. World Health Organization. Geneva: WHO Press. Retrieved from http://www.who. int/violence_injury_prevention/publications/road_traffic/distracted_driving_en.pdf.

World bank (n.d.). Individuals using the Internet (\% of population) | Data. Retrieved February 7, 2018, from https://data.worldbank.org/indicator/IT.NET. USER.ZS. 